\title{
Enhanced Mechanical Properties by Grain Boundary Strengthening in Ultra-Fine-Grained TZP Ceramics
}

\author{
Y. J. He, A. J. A. Winnubst, C. D. Sagel-Ransijn, A. J. Burggraaf \& H. Verweij \\ University of Twente, Faculty of Chemical Technology, Laboratory for Inorganic Materials Science, \\ PO Box 217, 7500 AE, Enschede, The Netherlands
}

(Received 10 March 1995; revised version received 18 July 1995; accepted 12 October 1995)

\begin{abstract}
The mechanical properties of ceramics with the compositions of $5 \mathrm{~mol} \% \mathrm{YO}_{1.5}-\mathrm{TZP}(\mathrm{ZY5})$ and 4 mol\% $\mathrm{YO}_{1.5}-4$ mol\% $\mathrm{CeO}_{2}-\mathrm{TZP}$ (ZY4Ce4) were investigated. Nanocrystalline powders of both $T Z P$ s were synthesized by a gel precipitation technique. Powder compacts were made by cold isostatic pressing, and were then pressureless sintered or sinter-forged to dense TZP ceramics (density: 96-99\%) with grain sizes of $180 \mathrm{~nm}$. Shear deformation during sinter-forging was found to favourably affect densification and microstructure. The mechanical properties of both types of ultrafine-grained TZP ceramics were examined up to $760^{\circ} \mathrm{C}$. The results point towards an improved grain boundary structure and the elimination of residual flaws obtained by the sinter-forging technique. The sinter-forged samples exhibited a higher Vicker hardness compared to that of pressureless sintered specimens. After sinter-forging the fracture energy value was found to be $325 \mathrm{~J} / \mathrm{m}^{2}$ and the fracture

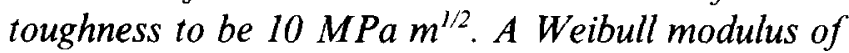
21 was obtained for the sinter-forged samples which was significantly higher than the value of 8 for the pressureless sintered specimens. The enhancement of reliability is obviously connected to a decrease in the average size and concentration of flaws caused by inhomogeneous powder particle packing due to the presence of irregular agglomerates.
\end{abstract}

\section{Introduction}

Typical requirements for structural ceramics are high strength, ductility, fracture resistance, chemical inertness and a stable microstructure. For a specific ceramic material, better properties can generally be obtained by improving microstructural characteristics such as grain size, homogeneity and distribution of porosity, and process flaws.
For fine-grained ceramics, grain boundaries have a considerable effect on the properties and performance of the materials. ${ }^{1,2}$ An example of this is the role of grain boundary morphology on fracture toughness. Watanabe et al. ${ }^{1,3}$ introduced the concept of grain boundary character distribution (GBCD) in alloy polycrystals. This distribution gives the frequency of specific grain boundary configurations and is an important tool in controlling intergranular fracture by grain boundary design. They pointed out that low-energy boundaries are resistant to fracture while high-energy (incoherent) boundaries are preferential sites for crack nucleation and propagation. The toughness of polycrystals increases with the relative fraction of low energy boundaries. A similar approach to grain boundary design for polycrystalline ceramics is also indicated by Krell et $a l^{4}{ }^{4}$ They suggested that the concept of grain boundary strength can be specified in three ways:

(l) As the critical stress intensity $k_{\mathrm{IC}}{ }^{\mathrm{gb}}$ required to propagate a crack along a grain boundary.

(2) As the specific fracture energy $\gamma^{\mathrm{gb}}$.

(3) As the local, microscopic (tensile) fracture stress $\sigma_{f}^{\mathrm{gb}}$.

The enhancement of the grain boundary strength for structural ceramics in the case of fracture controlled mainly by an intergranular mode will result in an improvement of mechanical properties, especially fracture toughness. High macroscopic strength is achieved, for instance, by reducing the concentration and size of flaws in the bulk ${ }^{5}$ or by limiting the possibility of, normally occurring, subcritical growth of extrinsic flaws. ${ }^{6}$

Recently the possibilities of using ultra-fine-grained ceramics or even nanocrystalline materials ${ }^{7.8}$ were explored. As suggested by Burggraaf $e t$ al. ${ }^{7,8}$ the characteristic features of nano-structured materials are:

- A significant fraction of atoms is situated in the grain boundary region and/or associated with interfacial effects. 
- An interaction exists between the constituent domains.

It is expected that ultra-fine-grained ceramics may possess special properties, related to the presence of a large grain boundary surface area. An examplc of this is surprisingly high superplastic deformation rates, obviously connected with short intergrain diffusion distances, observed by Bout $z$ et al. ${ }^{9}$ Very interesting high temperature mechanical properties are reported by Theunissen et al. ${ }^{10}$ They found that $\mathrm{Y}-\mathrm{TZP}$ ceramics with a smaller grain size exhibit a higher fracture toughness and bending strength at high temperature than those with a coarser grain size. Practical applications of nano-structured zirconia were limited up to now because it is difficult to produce them reproducibly with a high density ( $\geq 95 \%)$. This problem can be solved by the application of sinter-forging which is useful for the elimination of flaws and grain boundary reinforcement. ${ }^{2,11,12}$ Hence, sinterforging can be used to shift the full densification temperature for ceramics to a lower temperature, ${ }^{13,14}$ so that grain growth can be limited further. This makes it possible to prepare dense ceramics with grain sizes in the nano-scale region. For sinter-forged tetragonal zirconia materials with grain sizes of 100-200 nm, densities > 97\% are reported by Boutz et al. ${ }^{15}$ It has also been reported that ionic conduction properties are significantly influenced by sinter-forging due to the change of grain boundary properties. ${ }^{2}$ To our knowledge, effects of sinter-forging on mechanical strength and Weibull modulus (reliability) as well as on high temperature mechanical properties have not yet been reported before for tetragonal zirconia polycrystal (TZP) with ultra-fine structure.

The major objective of this study was to investigate the effects of sinter-forging and the influence of grain boundary properties and process flaws on fracture toughness, bending strength and Weibull modulus at temperatures up to $760^{\circ} \mathrm{C}$. The sinterforging technique was used to strengthen grain boundaries and consequently increase the mechanical properties. The effect of flaws on reliability of ceramics is discussed. Transmission electron microscopy (TEM), scanning electron microscopy (SEM), $\mathrm{X}$-ray photoelectron spectroscopy (XPS) and X-ray diffraction (XRD) were used to analyze the fracture surface, flaw size and grain boundary properties.

\section{Experimental Procedure}

\subsection{Powder preparation}

Nanocrystalline tetragonal zirconia powders with high sinter reactivity were synthesized by a gel precipitation technique using metal chloride pre- cursors. The materials studied were ZY5 $(5 \mathrm{~mol} \%$ $\left.\mathrm{YO}_{15}-\mathrm{TZP}\right)$ and $\mathrm{ZY} 4 \mathrm{Ce} 4$ (4 mol\% $\mathrm{YO}_{15}-4 \mathrm{~mol} \%$ $\left.\mathrm{CeO}_{2}-\mathrm{TZP}\right)$. The precursor solution was dropped slowly into an excess of a $25 \mathrm{wt} \%$ ammonia solution with $\mathrm{pH}>11$. The formed gel was washed subsequently with a water/ammonia mixture solution to remove $\mathrm{Cl}^{-}$. Washing with ethanol was then used to remove the free water. A more detailed process has been given by Groot Zevert $e t$ $a l^{16}$ The dried gel was calcined subsequently at $500^{\circ} \mathrm{C}$ for $2 \mathrm{~h}$ followed by milling procedure using $\mathrm{ZrO}_{2}$ balls. Compacts were made by cold isostatically pressing at $50 \mathrm{MPa}$ and crushed again in an alumina mortar to obtain better powder flowability. This powder was uniaxially pressed at $80 \mathrm{MPa}$ in a die to form a rectangular shape which was compacted further by cold isostatical pressing (CIP) at $400 \mathrm{MPa}$. The compacts were pressureless sintered in air at $1150^{\circ} \mathrm{C}$ for $10 \mathrm{~h}$ with heating and cooling rates of $2^{\circ} \mathrm{C} / \mathrm{min}$.

\subsection{Sinter-forging}

The samples for sinter-forging experiments were pre-sintered by a heating rate of $2^{\circ} \mathrm{C} / \mathrm{min}$ to $1000^{\circ} \mathrm{C}$ for 15 min to improve compact strength. The density changed from $46 \%$ for the initial green body after CIP to $64 \%$. These samples were subsequently machined to $26 \times 8 \times 6 \mathrm{~mm}^{3}$ with plane-parallel $26 \times 6 \mathrm{~mm}^{2}$ sides. Sinter-forging experiments were performed in air at $1150^{\circ} \mathrm{C}$ under a constant load corresponding to an initial stress of $90 \mathrm{MPa}$. The initial stress is defined with respect to dimensions just before loading. The sinter-forging heating schcdule was: heating from ambient temperature to $950^{\circ} \mathrm{C}$ at $600^{\circ} \mathrm{C} / \mathrm{h}$ and then to $1150^{\circ} \mathrm{C}$ at $300^{\circ} \mathrm{C} / \mathrm{h}$. The load was imposed on the $26 \times 6 \mathrm{~mm}^{2}$ plane of the samples and raised linearly at $1150^{\circ} \mathrm{C}$ from zero to its final value in $5 \mathrm{~min}$ and then kept constant for $25 \mathrm{~min}$. Details of the sinter-forging setup are given in Refs. 13, 14 and 17.

\subsection{Characteristics}

The densities of the green and sintered compacts were measured by the Archimedes technique in $\mathrm{Hg}$. The bending strength was measured by the 4-point bending technique with an inner and outer span of 10 and $20 \mathrm{~mm}$, respectively, using a crosshead speed of $0.7 \mathrm{~mm} / \mathrm{min}$. The specimens for bending strength measurement were cut into $26 \times 5 \times 2 \mathrm{~mm}^{3}$ bars and polished on the $26 \times 5$ $\mathrm{mm}^{2}$ side opposite to the loading piston (hence subjected to tensile stress). After machining and polishing, all specimens were annealed for $10 \mathrm{~min}$ at $1000^{\circ} \mathrm{C}$ with heating and cooling at $2.5^{\circ} \mathrm{C} / \mathrm{min}$. The fracture toughness, $K_{\mathrm{IC}}$, was measured by the 3-point single-edge notched beam (SENB) method 
with a span of $12 \mathrm{~mm}$, a crosshead speed of 0.3 $\mathrm{mm} / \mathrm{min}$ and $15 \times 3 \times 1 \mathrm{~mm}^{3}$ specimens. A notch of $450 \mu \mathrm{m}$ depth and $50 \mu \mathrm{m}$ width was cut without pre-cracking at the notch tip. After machining, the samples were annealed at $1000^{\circ} \mathrm{C}$ in the same way as mentioned before.

The phase composition was measured on polished and annealed surfaces as well as on fractured surfaces by means of X-ray diffraction using $\mathrm{CuK} \alpha$ radiation (Philips PW1710 X-ray diffractometer with a step scan size of $0.015^{\circ}(2 \theta)$. The method proposed by Toraya ${ }^{18}$ was used to determine the volume fraction of monoclinic zirconia. The microstructures of polished surfaces and fractured surfaces were analyzed by SEM (JSM-35CT, JEOL). The grain sizes of the sintered ceramics were measured by the linear intercept method from SEM photographs. ${ }^{19}$ The grain boundary structure of sinter-forged materials was analyzed by transmission electron microscopy (TEM).

\subsection{Weibull modulus}

Weibull statistics were used in describing the strength distribution in ceramics. The statistical strength values obtained from testing of ceramics were analyzed using the cumulative probability parameter, $P(\sigma)$. This is the probability of failure at a stress $\leq \sigma$ and is given in Ref. 20:

$$
\frac{1}{1-P(\sigma)}=\exp \left(\frac{\sigma}{\sigma_{0}}\right)^{m}
$$

where $\boldsymbol{m}$ is the Weibull modulus, which is a slope obtained from a plot of $\ln \{\ln (1 /(1-P(\sigma))\}$ against $\ln (\sigma)$ curves. $\sigma_{0}$ is a scale parameter with the same dimension as $\sigma$.

The estimator of the cumulative probability parameter was calculated by:

$$
P_{j}=\frac{j \quad 0 \cdot 5}{n}
$$

where the $j$ th result in the set of $n$ samples is assigned a cumulative probability of failure, $P_{j}$. This was done by ordering the results of the stresses to rupture from the lowest to the highest values. This probability parameter $P(\sigma)$ is generally fitted to the modulus of rupture (MOR) test data, which were the four-point bending strength, $\sigma$, of a set of bars of the test materials.

\subsection{Micro-hardness}

The hardness of a solid is generally defined as a resistance to local deformation. ${ }^{21}$ In this study, the classical Vickers hardness $\left(H_{\mathrm{V}}\right)$ was measured by a microhardness equipment (Shimadzu DUH-200, Japan). During the measurement, typical loading-unloading curves were recorded using a maxi- mum load of $2 \mathrm{~N}$ with a loading speed of $14.4 \times$ $10^{-2} \mathrm{~N} / \mathrm{s}$ and a hold time of $5 \mathrm{~s}$ at the maximum load. Using this equipment, the Vickers hardness $\left(H_{\mathrm{V}}\right)$ was determined by the average values of both diagonals with a Vickers indenter apex of $136^{\circ}$ and calculated with

$$
H_{\mathrm{V}}=1.8544 \frac{F}{d^{2}}
$$

where $F$ is the load $(\mathrm{N})$, and $d$ is the mean value of both diagonals.

The measured Vickers hardness values $\left(H_{\mathrm{V}}\right)$ in Table 1 were nearly the same as the results (HV10) obtained by a macroindenter (Isser Stedt Garant 250RD) at a load of $100 \mathrm{~N}$ (10 kgf).

\section{Experimental Results}

\subsection{Powder characteristics and densification}

No significant differences in powder properties were found for the ZY5 and ZY4Ce4 systems. A crystallite size of $8 \mathrm{~nm}$ for both ZY5 and ZY4Ce4 powders was calculated from X-ray line broadening data (XRLB) by using the Scherrer equation $^{22}$ and measured from TEM micrographs. ${ }^{23}$ For the same powder a large average agglomerate sizc of $15 \mu \mathrm{m}$ is obtained by a laser diffraction particle size distribution analyzer (Horriba LA-500). Weak agglomerates can be fragmented gradually during isostatic compaction at a certain minimum pressure, $P_{\mathrm{y}}$, which is defined as the agglomerate strength. ${ }^{10}$ For both powders, $P_{\mathrm{y}}$ was found to be 70-90 MPa, but certain hard agglomerates still remained at this pressure. Relative densities of ZY4Ce4 during pressureless sintering and sinterforging (at $90 \mathrm{MPa}$ ) at $1150^{\circ} \mathrm{C}$ are shown as a function of time in Fig. 1. The densification kinetics are significantly enhanced by creep deformation under a uniaxial pressure of $90 \mathrm{MPa}$ (sinter-forging) as compared to pressureless sintering. After sinter-forging for $25 \mathrm{~min}$, a creep strain of 0.5 and a density of $98-99 \%$ were reached. After pressureless sintering, however, a density of only 93-94\% was obtained. To achieve a density of $96-97 \%$ by pressureless sintering at $1150^{\circ} \mathrm{C}, 600$ min dwell time was required as seen in Table 2. Prolonged sintering did not result in any further density increase. Similar results were obtained for ZY5.

Table 1. The microhardness of TZP materials

\begin{tabular}{ccc}
\hline Sample & SF/PS & $\mathrm{H}_{\mathrm{v}}(\mathrm{GPa})$ \\
\hline ZY5 & SF & $14 \cdot 2 \pm 0 \cdot 5$ \\
ZY5 & PS & $13 \cdot 3 \pm 0 \cdot 4$ \\
ZY4Ce4 & SF & $13 \cdot 6 \pm 0 \cdot 3$ \\
ZY4Ce4 & PS & $12 \cdot 5 \pm 0 \cdot 6$ \\
\hline
\end{tabular}


Densification of $\mathrm{ZY} 4 \mathrm{C} \theta 4$ at $1150^{\circ} \mathrm{C}$

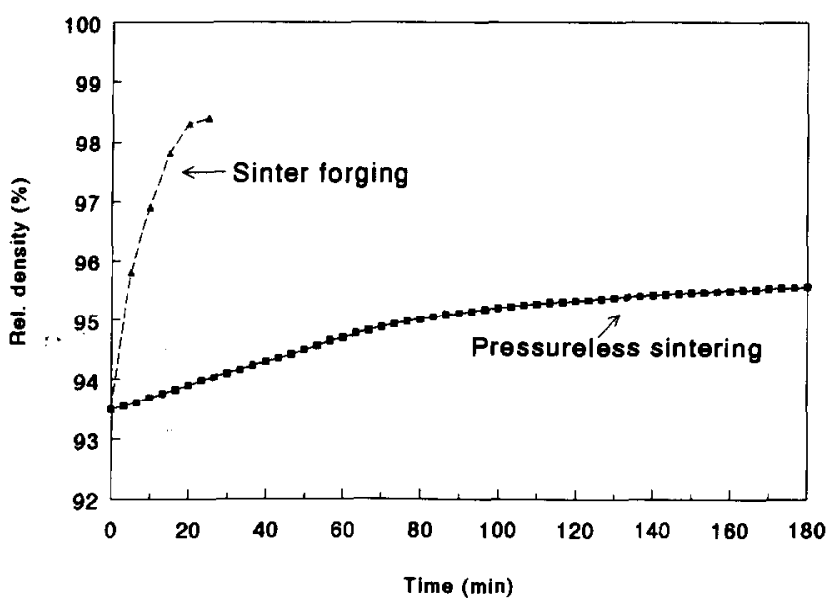

Fig. 1. Densification behaviour of ZY4Ce4 during sinter-forging and pressureless sintering. The samples were performed by sinter-forging at $90 \mathrm{MPa}$ initial pressure.

Micrographs of ZY5 samples sinter-forged and pressureless sintered at $1150^{\circ} \mathrm{C}$ are shown in Fig. 2 . Grain sizes of 0.18 and $0.19 \mu \mathrm{m}$ were obtained for ZY5 and ZY4Ce4, respectively (Table 2). XRD analysis revealed that in all cases only a tetragonal phase was present. The residual pore sizes are less than the grain sizes in both sinter-forged and pressureless sintercd samples. The microstructure obtained, however, showed large differences. At low magnification, some pore-like or crack-like

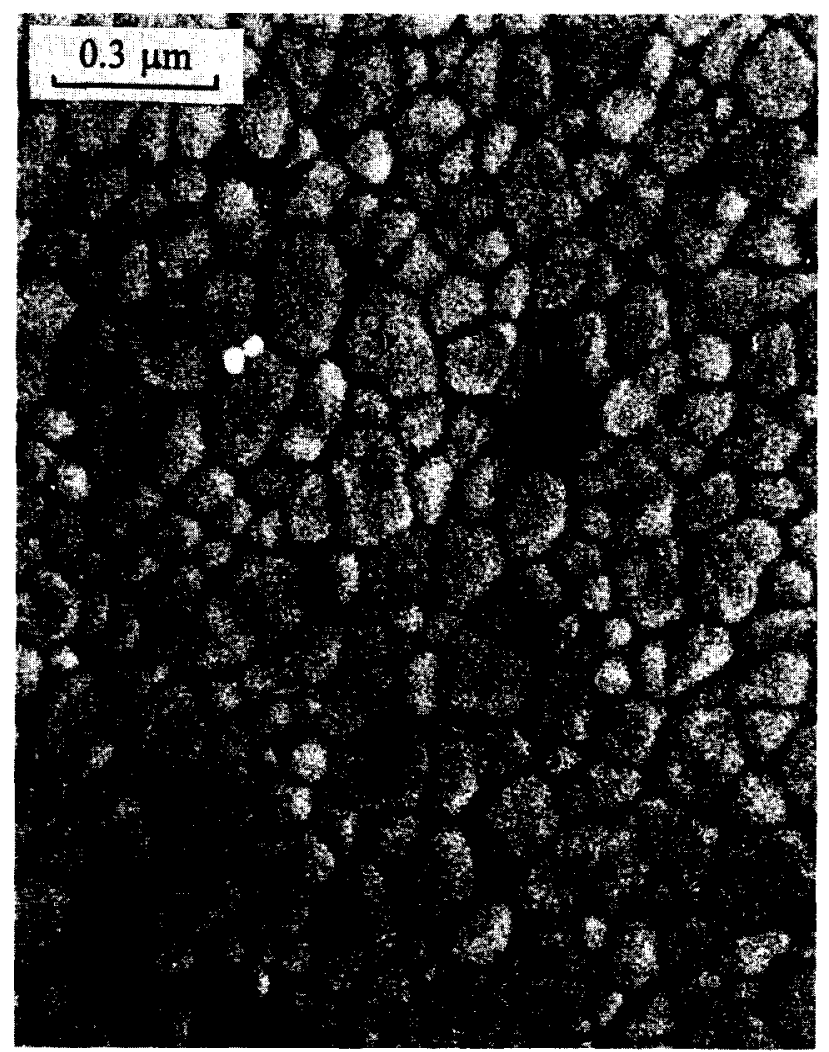

(a)
Table 2. Properties of sinter-forged (SF) TZPs (25 min) and pressureless sintered (PS) TZPs $(600 \mathrm{~min})$ at $1150^{\circ} \mathrm{C}$

\begin{tabular}{cccc}
\hline Sample & SF/PS & Density (\%) & Grain size $(\mu m)$ \\
\hline ZY5 & SF & 98.5 & 0.18 \\
ZY5 & PS & $96-97$ & 0.18 \\
ZY4Ce4 & SF & 98.5 & 0.19 \\
ZY4Ce4 & PS & 97 & 0.19 \\
\hline
\end{tabular}

flaws (the largest about $60 \mu \mathrm{m}$ ) were present in the pressureless sintered samples as seen in Fig. 3. Such large flaws were also found by Boutz et al. ${ }^{13}$ in Y-TZP pressureless sintered at the same conditions. Such flaws, however, were not found in sinter-forged TZP, in agreement with the observations for sinter-forged ZTA (zirconia-toughened alumina) ceramics. ${ }^{11}$

\subsection{Effects of grain boundary structure on hardness} Vickers hardness values are given in Table 1. These results show that the Vickers hardness for sinter-forged ZY5 and ZY4Ce4 samples is higher than that of the pressureless sintered samples. In all cases ZY5 has a slightly higher Vicker hardness than ZY4Ce4. The Vickers hardness can be considered as the resistance to plastic deformation. Thus a higher resistance to plastic deformation is obtained by sinter-forging compared to pressureless sintering.

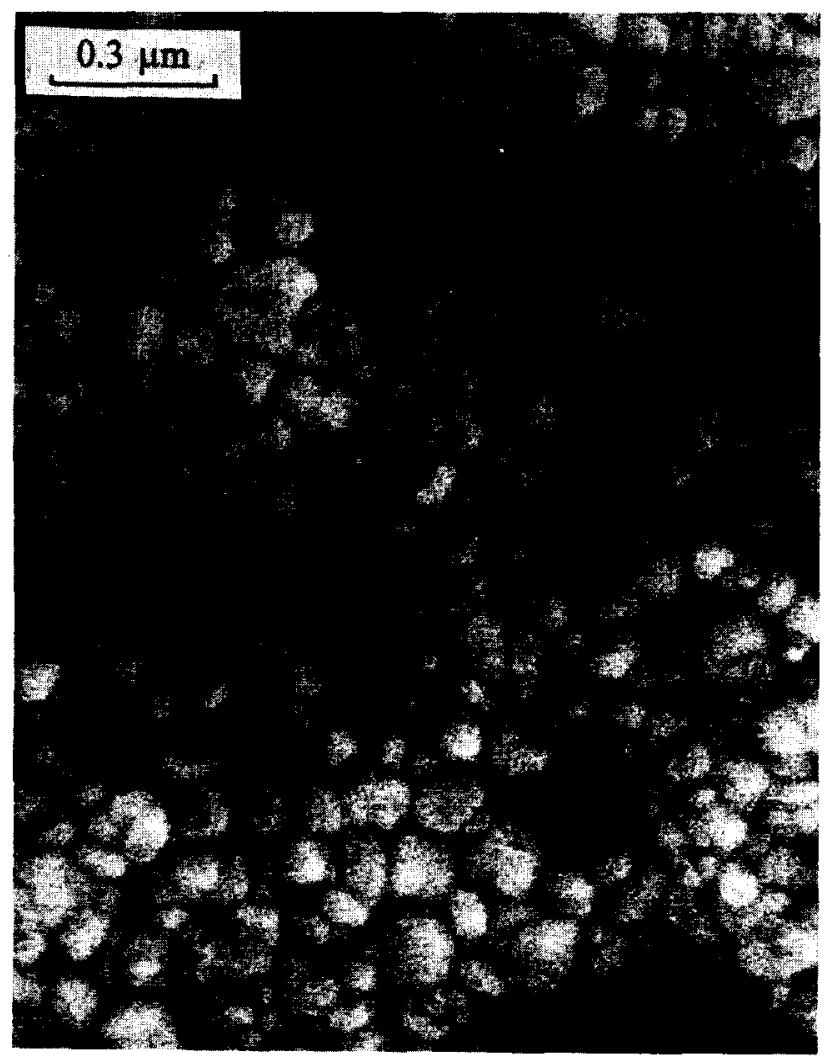

(b)

Fig. 2. Example of the microstructure of ZY5 samples after sintering at $1150^{\circ} \mathrm{C}$ : (a) for 25 min by sinter forging, and (b) for 600 min by pressureless sintering. 
The hardness of a given material is related to microstructural parameters such as porosity, grain size, grain boundary properties and preexist dislocation structure as indicated by Krell. ${ }^{24}$ In the present study the grain size is equal in all cases, thus grain size effects on hardnesses are eliminated. A possible difference in preexist dislocations between pressureless sintered and sinter-forged specimens is not expected as will be discussed now. Boutz et $a l^{9.13}$ point out that the plastic deformation of fine-grained Y-TZP takes place by interface reaction controlled grain boundary sliding. During this process the shape of the crystals does not change. That means an absence of dislocation creep. These arguments certainly hold for sinterforging at low temperature. Bulk dislocation mobility is very low especially for the small crystals considered here. Hence, dislocations are unlikely to affect the hardness in the sinter-forged specimens. It is more likely that the differences in microhardness values between sinter-forged and pressureless sintered specimens can be ascribed to the porosity of the bulk and the property of the grain boundaries. It was attributed to the fact that the microhardness measurements were performed on parts of the microstructure without flaws. So the effect of porosity caused partly by local flaws in the pressureless sintered samples can be ignored for these microhardness measurements. Grain boundary properties such as bonding strength and micropores (or microdefects) at grain boundaries

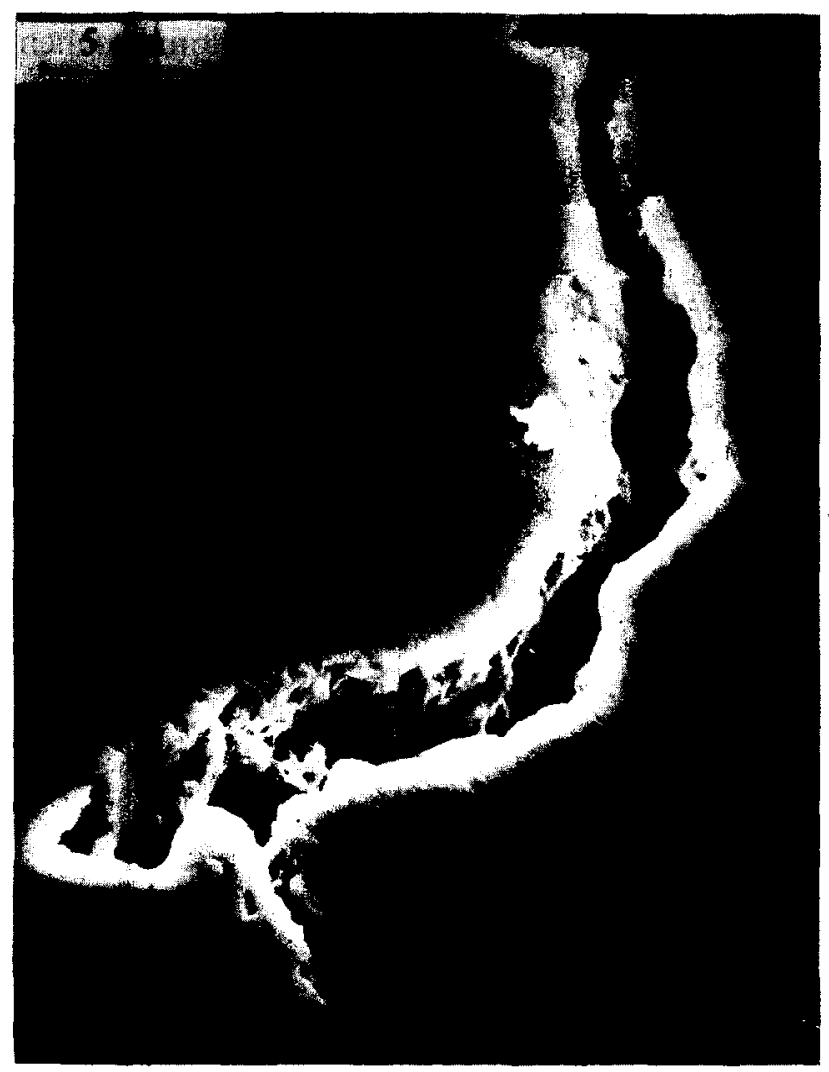

Fig. 3. A typical cracklike defect is presented on the surface of pressureless sintered ZY5 samples. are thus the major factors that affect the hardness values. For a given $\mathrm{ZY} 5$ or $\mathrm{ZY} 4 \mathrm{Ce} 4$ material, the difference in the Vickers hardness between sinterforged and pressureless sintered samples is related to the bonding strength and micropores of the grain boundaries as will be discussed later.

\subsection{Influence of strengthened grain boundaries on fracture toughness}

The fracture toughness results are given as a function of temperature in Fig. 4. Sinter-forged samples show higher toughness values than pressureless sintered samples at all temperatures. $\mathrm{X}$-ray diffraction results on polished surfaces and even on a ground surfaces do not show any monoclinic zirconia. This clearly indicates that no precompressive stresses at the notch tip due to machining-induced transformation can influence the mechanical properties. By XRD analyses, no monoclinic phase was detected at the fractured surface. This means that no irreversible phase transformation occurs during fracturing. As discussed by Boutz et al.,$^{13}$ for ultra-fine-grained TZP materials, the occurrence of reversible transformation toughening is a matter of debate, and crack deflection is commonly suggested as the toughening mechanism in this case. The toughening mechanism for all TZPs investigated in this work is expected to be the same for pressureless sintered and sinter-forged samples. So for sinter-forged samples an additional toughening mechanism should be present.

The observation of the fracture surfaces (Fig. 5) gives a clue to consider this difference between sinter-forging and pressureless sintering. All these surfaces show a considerable fraction of intergranular fracture. Hence the grain boundaries play an important role in the development of the fracture process. The fracture energy, $\gamma_{\mathrm{f}}$ necessary to create a unit area of new fracture surface, is directly related to $K_{\mathrm{IC}}$ at plane stress conditions by:

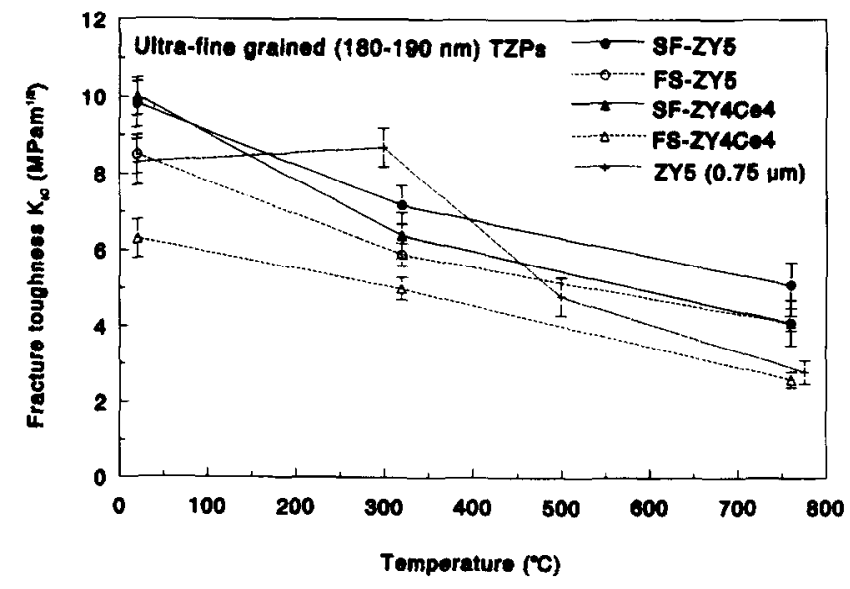

Fig. 4. Fracture toughness of ZY5 and ZY4Ce4 obtained by pressureless sintering and sinter-forging as a function of temperature. 


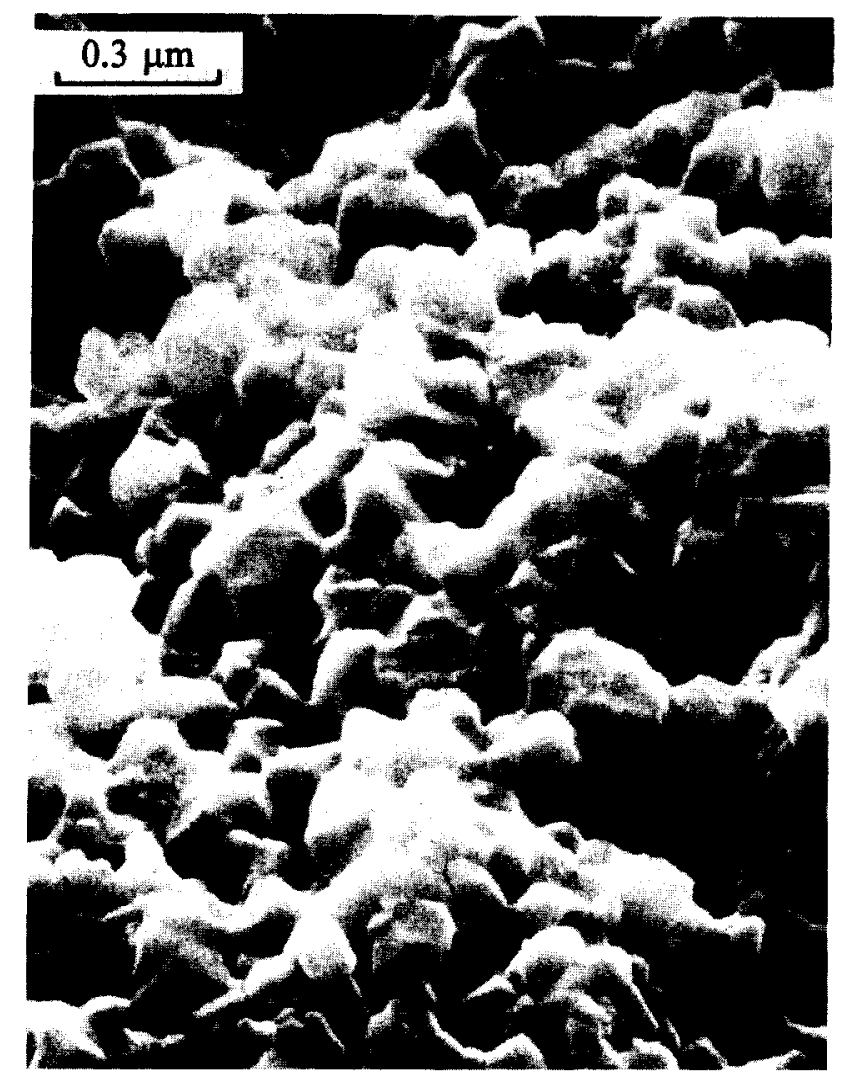

(a)

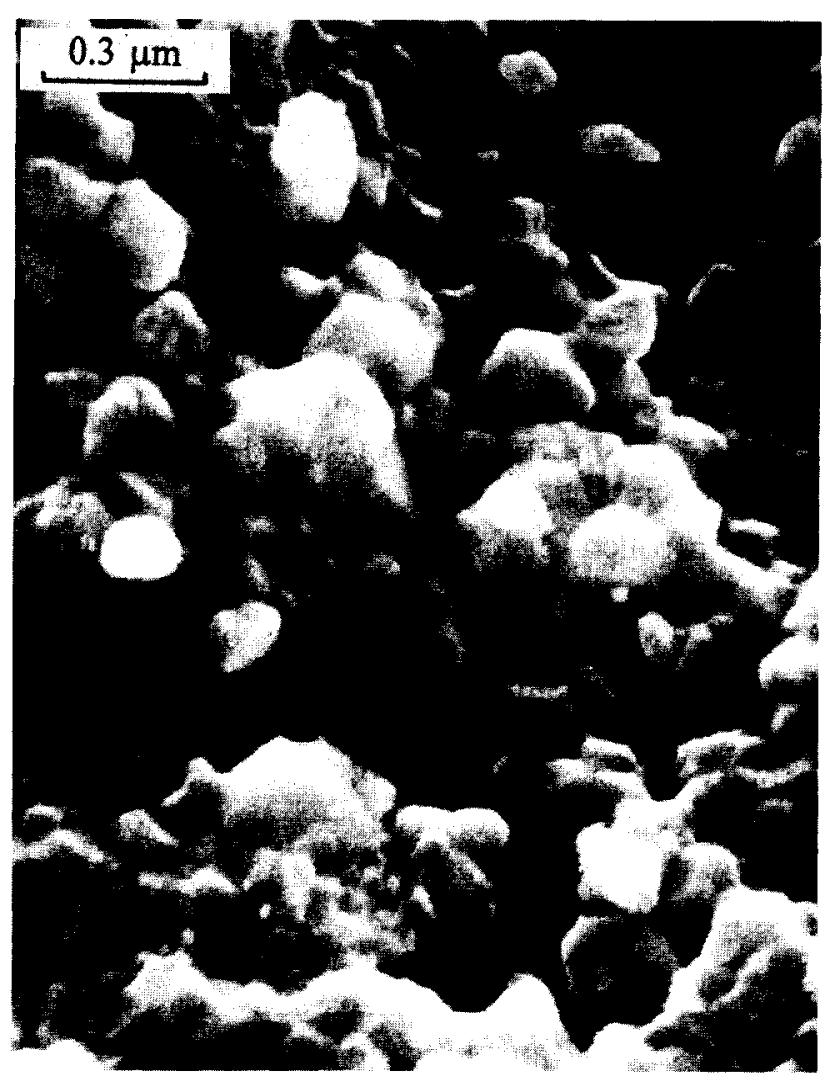

(b)

Fig. 5. Fracture surface of ZY 5 sintered by (a) sinter-forging and (b) pressureless sintering, fractured at room temperature.

$$
\gamma_{\mathrm{f}}=\frac{K_{\mathrm{IC}}^{2}}{2 E}
$$

where $E$ is Young's modulus. An enhancement of $\gamma_{\mathrm{f}}$ can be caused by reduced porosity and strengthened grain boundaries. In order to compare the influence of the grain boundaries on $\gamma_{f}$ in sinter-forged samples with that in pressureless sintered samples, it is necessary to eliminate the influence of porosity. Normally, the fracture energy, $\gamma_{\mathrm{f}}$, as a function of the residual porosity $(P)$ is given as: ${ }^{25}$

$$
\gamma_{\mathrm{f}}=\gamma_{0} \exp (-b P)
$$

where $\gamma_{0}$ is the fracture energy of a fully dense material and $b$ is a numerical constant, found to be 3.4 by Boutz et al. ${ }^{13}$ In Table 3, the calculated $\gamma_{0}$ values are given for $100 \%$ density for both sinter-forged and pressureless sintered samples, whereas the primary data are the measured $K_{\mathrm{IC}}$. The $\gamma_{0}$ data (see Table 3 ) indicate that there is a significant increase in fracture energy after sinterforging. This increase can be ascribed only to grain boundary strengthening. It is noted again that no reversible phase transformation toughening was observed in these materials.

\subsection{Influence of flaws on reliability and flexural strength}

In Fig. 6 the flexural strength is given for ZY5 as a function of temperature. The flexural strength gradually decreases with increasing temperature in both sinter-forged and pressureless sintered specimens because grain boundary bonding becomes weaker with increasing temperature. This variation of flexural strength as a function of temperature is the same as that obtained by Theunissen. ${ }^{10}$

\begin{tabular}{|c|c|c|c|c|c|}
\hline \multirow[t]{2}{*}{ Sample } & \multirow{2}{*}{$\begin{array}{l}\mathrm{T}_{\text {fract. }} \\
\left({ }^{\circ} \mathrm{C}\right)\end{array}$} & \multicolumn{2}{|c|}{$\begin{array}{l}\text { Fracture energy } \\
\quad \gamma_{O}\left(\mathrm{~J} / \mathrm{m}^{2}\right)\end{array}$} & \multicolumn{2}{|c|}{$\begin{array}{c}\mathrm{K}_{I C} \\
\left(M P a m^{1 / 2}\right)\end{array}$} \\
\hline & & $S F$ & $F S$ & $S F$ & $F S$ \\
\hline ZY5 & 20 & 297 & 209 & $9.8 \pm 0.6$ & $8.5 \pm 0.5$ \\
\hline ZY5 & 320 & 160 & 101 & $7.2 \pm 0.5$ & $5.9 \pm 0.3$ \\
\hline ZY5 & 760 & 81 & 49 & $5 \cdot 1 \pm 0 \cdot 6$ & $4.1 \pm 0.6$ \\
\hline ZY4Ce4 & 20 & 325 & 126 & $10.0 \pm 0.5$ & $6.3 \pm 0.5$ \\
\hline $\mathrm{ZY} 4 \mathrm{Ce} 4$ & 320 & 133 & 80 & $6.4 \pm 0.7$ & $5 \cdot 0 \pm 0.3$ \\
\hline ZY4Ce4 & 760 & 55 & 21 & $4 \cdot 1 \pm 0.2$ & $2.6 \pm 0.2$ \\
\hline
\end{tabular}

Table 3. Fracture energies and toughness values of all investigated TZP materials 


\section{4-point bending strength}

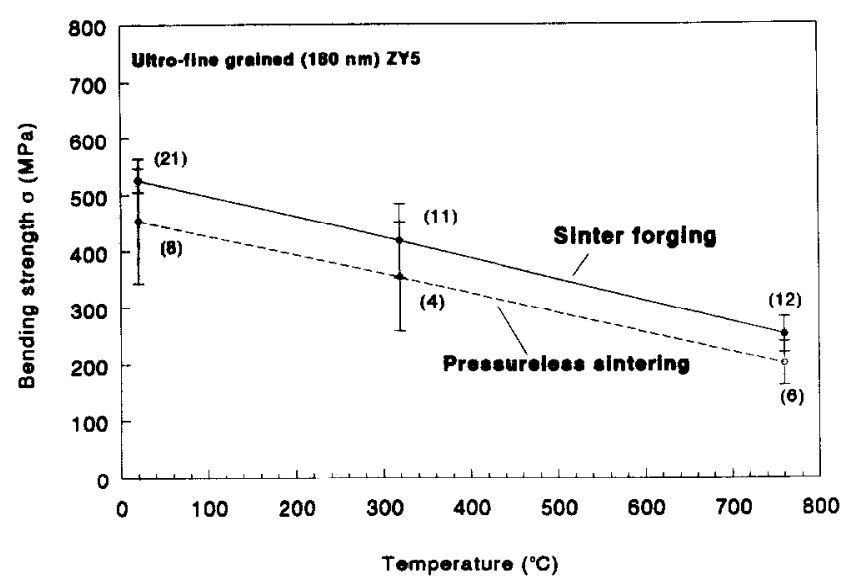

Fig. 6. Flexural strength (4-point bending strength) for sinterforged or pressureless sintered ZY5 as function of temperdture. The values in parenthesis represent the Weibull modulus.

A slightly higher flexural strength for sinter-forged samples as compared with pressureless sintered samples is observed for the full temperature region regarded $\left(20-760^{\circ} \mathrm{C}\right)$. The Weibull modulus, $m$, as obtained from a Weibull plot of the flexural strength, is given in Table 4. Ten samples were used for both cases of sinter-forging and pressureless sintering. At room temperature, $m$-values of 21 and 8 are obtained after sinter forging and pressureless sintering, respectively. The results reveal a significant increase in the Weibull modulus for the sinter-forged samples. In all cases the Weibull modulus decreases with temperature (Table 4). It is concluded that the reliability of sinter-forged TZP ceramics is higher than pressureless sintered ones. It is well known that the bending strength of ceramics is highly sensitive to the flaws in bulks.

To investigate the effect of flaws on the reliability of materials, the fracture origins were examined by SEM. Typical morphologies of the fracture surface of pressureless sintered ZY5 samples are given in Fig. 7. As can be seen there are some Wallner lines around a certain part in the fractural surface (Fig. 7(a)). A large flaw is found at the beginning of these Wallner lines. At larger

Table 4. Values of the Weibull modulus of both sinter-forged and pressureless sintered TZP ceramics

\begin{tabular}{cccc}
\hline \multirow{3}{*}{ Sample } & \multicolumn{3}{c}{ Weibull modulus } \\
\cline { 2 - 4 } & $R T$ & $320^{\circ} \mathrm{C}$ & $760^{\circ} \mathrm{C}$ \\
\hline FS-ZY5 & 8 & 4 & 6 \\
SF-ZY5 & 21 & 11 & 12 \\
\hline
\end{tabular}

RT: room temperature.

FS: free sintering.

SF: sinter-forging. magnification it can be seen that this large flaw is a porous zone (Fig. 7(b)). Such porous zones are hardly found in sinter-forged samples (Fig. 7(c)). The same observation is made for a large area of the fracture surface of $\mathrm{ZY} 4 \mathrm{Ce} 4$ samples as can be seen in Fig. 8. The fracture surface of the sinterforged samples always shows a homogenous fracture surface (Fig. 8(a)), while in pressureless sintered samples it is easy to trace the stress concentration back to a specific flaw (Fig. 8(b)). As indicated in Section 3.1, crack-like or pore-like fracture origins, are present in the pressureless sintered samples and are caused by inhomogeneous sintering due to inhomogeneous packing of the green compact, while these flaws are suppressed or eliminated by a large shear deformation imposed on the material during sinter-forging. Microstructural observations indicate that the maximum dimension of the crack- or pore-like flaws is about $60 \mu \mathrm{m}$ in pressureless sintered samples. In the sinter-forged samples, however, only residual pores are present, of which sizes are less than the grain size.

Another type of flaw is found in both sinterforged and pressureless sintered samples (Fig. 9). Large dense, irregular-shaped particles are observed that are coherent with the local matrix. EDX analysis indicate a high $\mathrm{Al}$ content so that these particles are referred to as alumina inclusions. They are likely to originate from the alumina mortar used during sample preparation in the compaction-grinding-compaction processes and cannot be eliminated by the sinter-forging technique. These inclusion flaws also serve as failure initiation sites with dimensions of 25-120 $\mu \mathrm{m}$. Nevertheless, the elimination of more severe flaws as shown in Figs 3 and 7 results in a higher Weibull modulus, enhancing the reliability of the materials after sinter-forging.

\section{Discussion}

A nearly theoretical density and a flaw-free microstructure are favourable in many applications of engineering ceramics. The sinterability of ceramics and the development of the final microstructure depend on the homogeneity of the pore structure in the green compacts. As suggested by Burggraaf et $a l^{7,8}$ a mild disorder in the green compact is preferred to obtain a homogeneous structure throughout the bulk and to minimize the size and concentration of defects. Long-range density fluctuations in the green compact may lead to the development of structural defects in materials during the sintering process. The density fluctuations are mainly caused by the presence of residual 


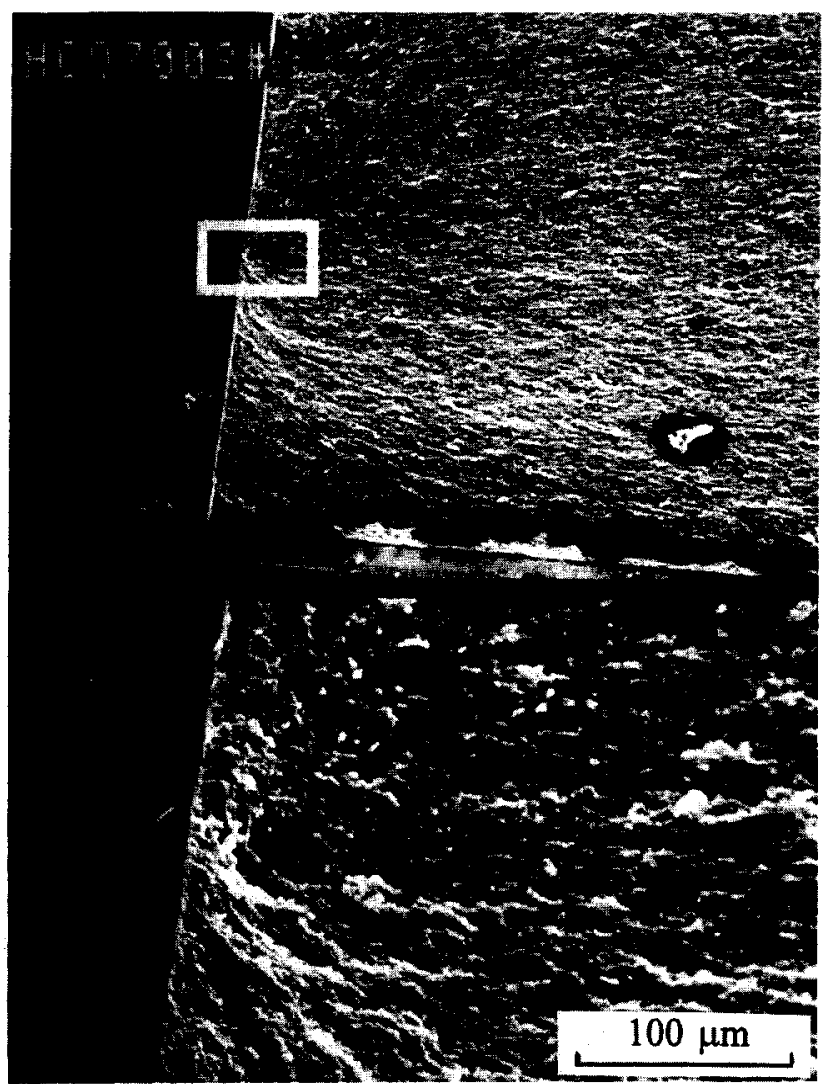

(a)

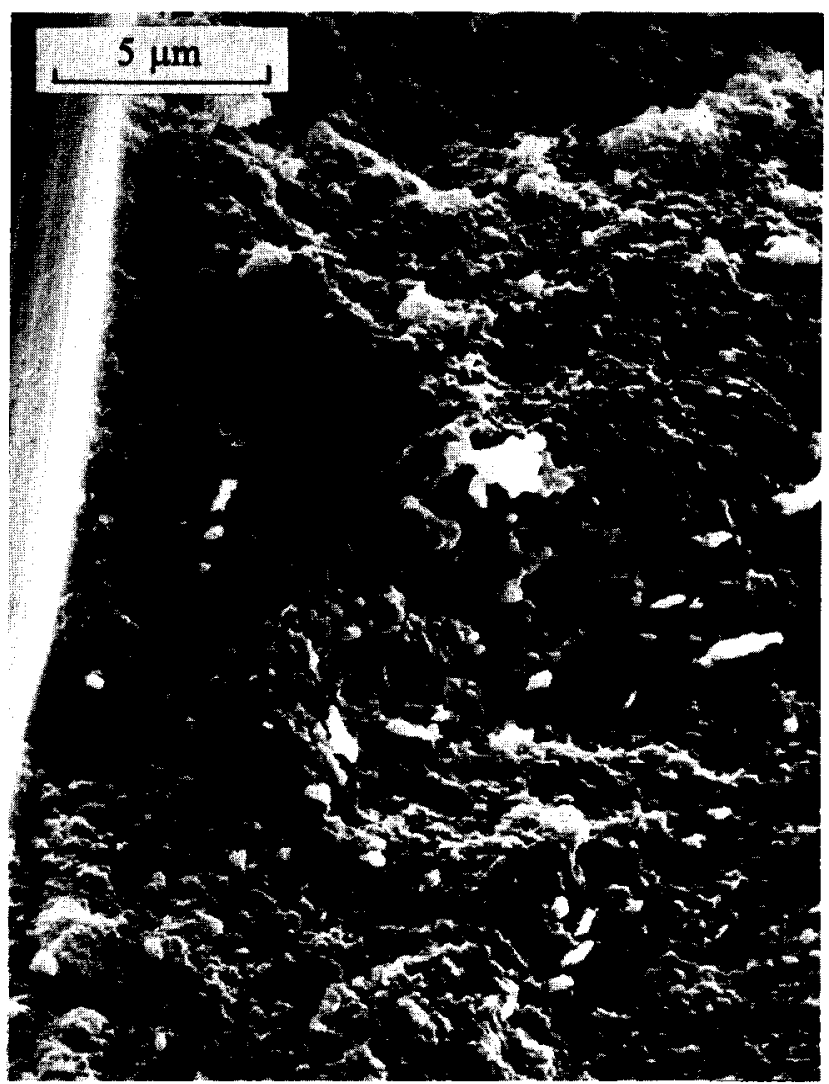

(b)

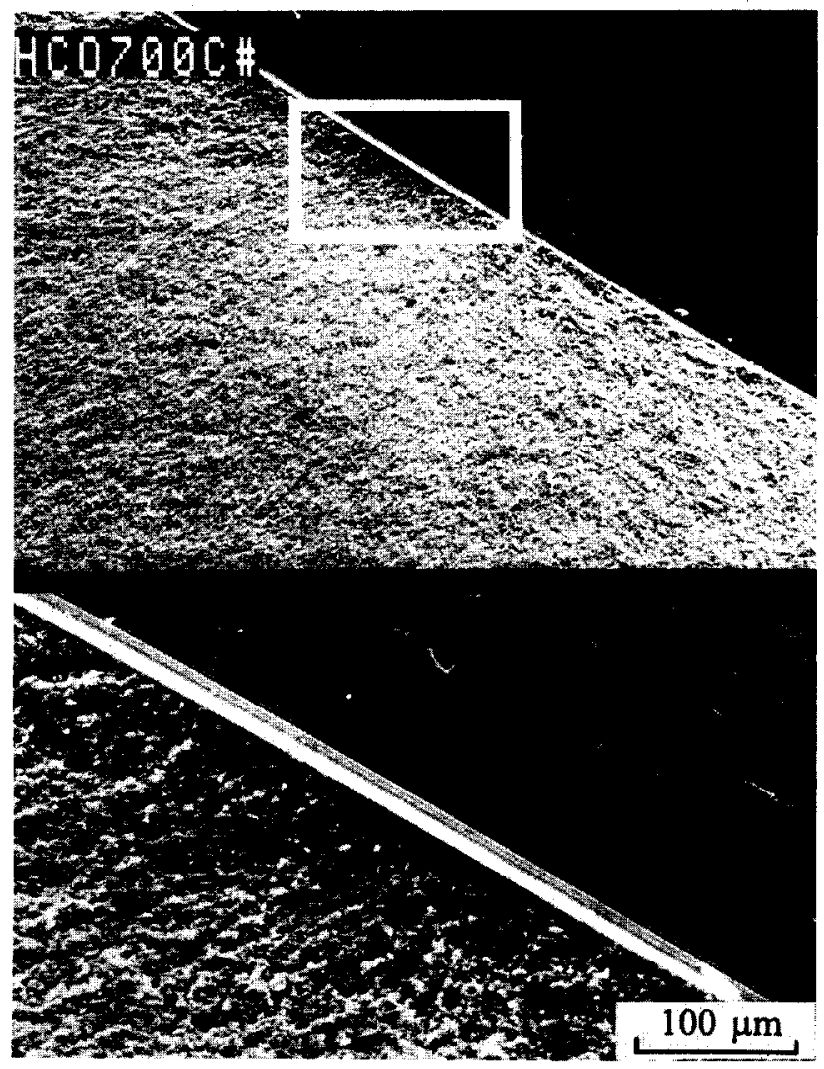

(c)

Fig. 7. Fracture surfaces of a ZY5 sample. (a) A flaw (indicated by the square) is surrounded by stress lines in pressureless sintered samples; (b) the large magnification of (a) shows a defect formed by a porous zone; (c)the sinter-forged samples.

agglomerates and/or other inhomogeneous particle packing structures.

Long-range density fluctuations result in local differences in the densification rate finally result- ing in local residual tensile stresses. ${ }^{26}$ The occurrence of such stresses during sintering may give rise to crack-like flaws or pore-like cavities. ${ }^{11,27}$ The occurrence of porous zone flaws can be con- 


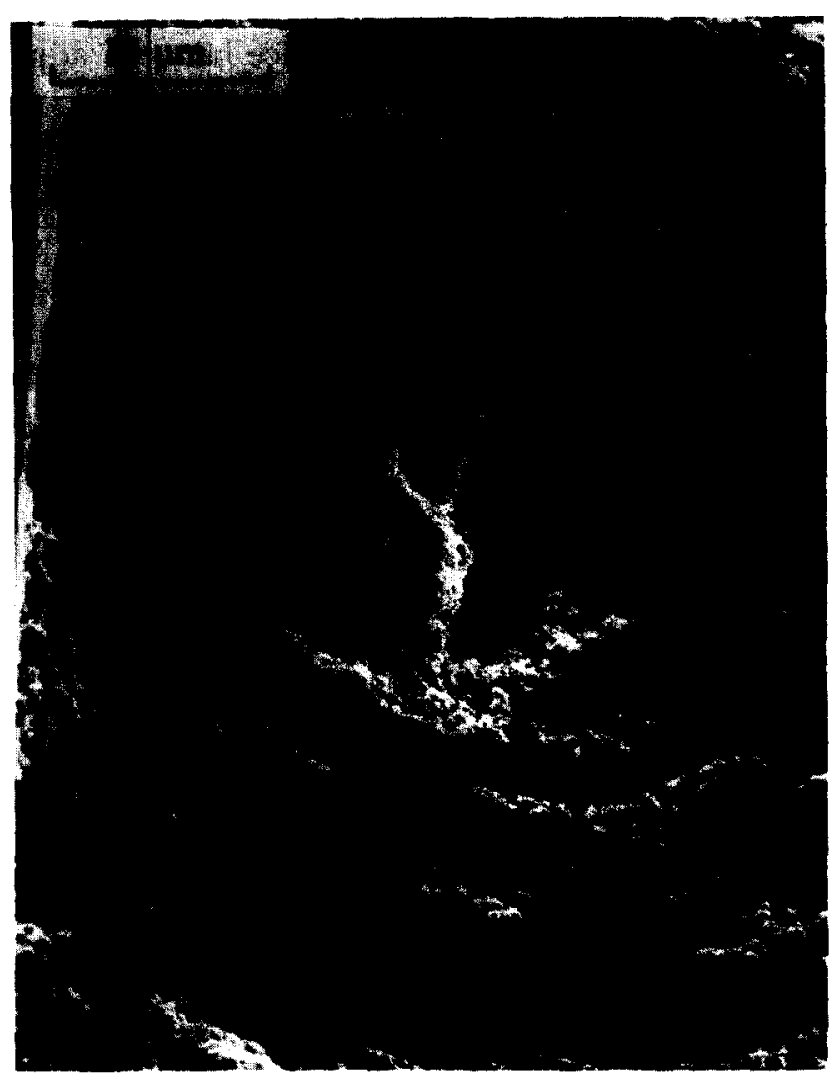

(a)

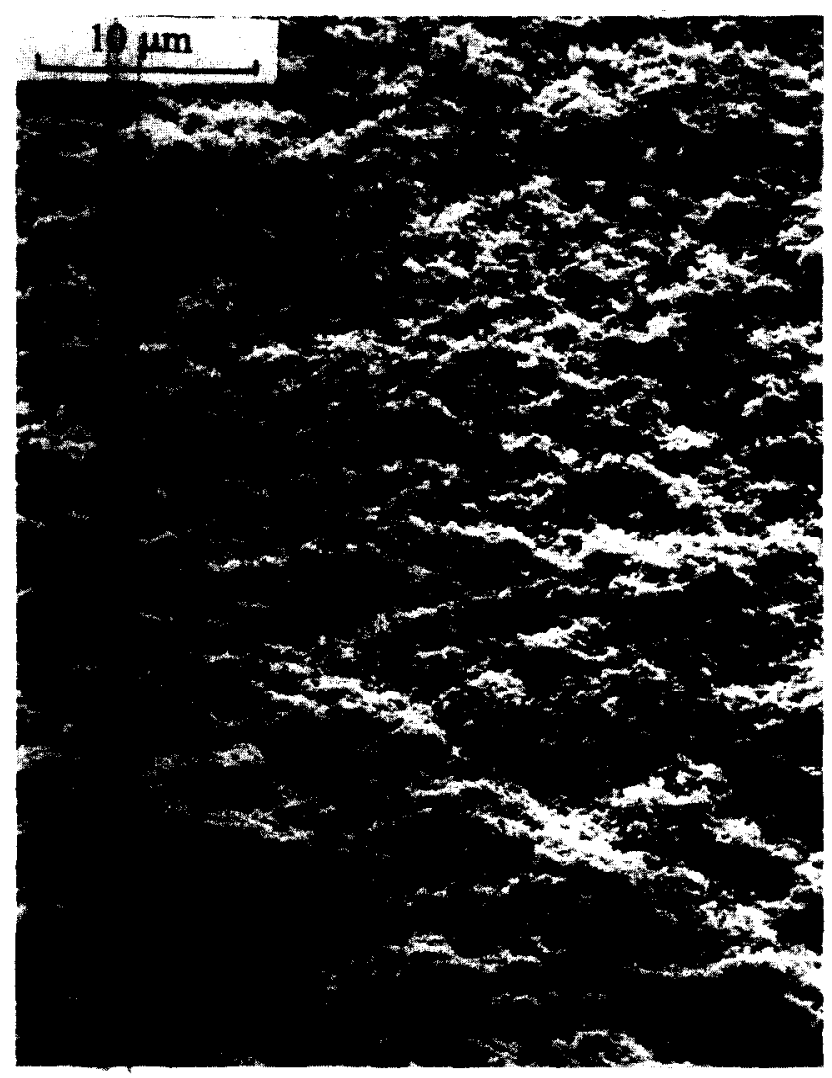

(b)

Fig. 8. Fracture surfaces of a $\mathrm{ZY} 4 \mathrm{Ce} 4$ sample. (a) A large area of the fracture surface in pressureless sintered samples; (b) a large area of the fracture surface in sinter-forged samples.

sidered as being due to major inhomogeneities. The formation of processing flaws during densification makes it difficult to obtain dense materials with an ultra-fine or even nano-scale microstruc-

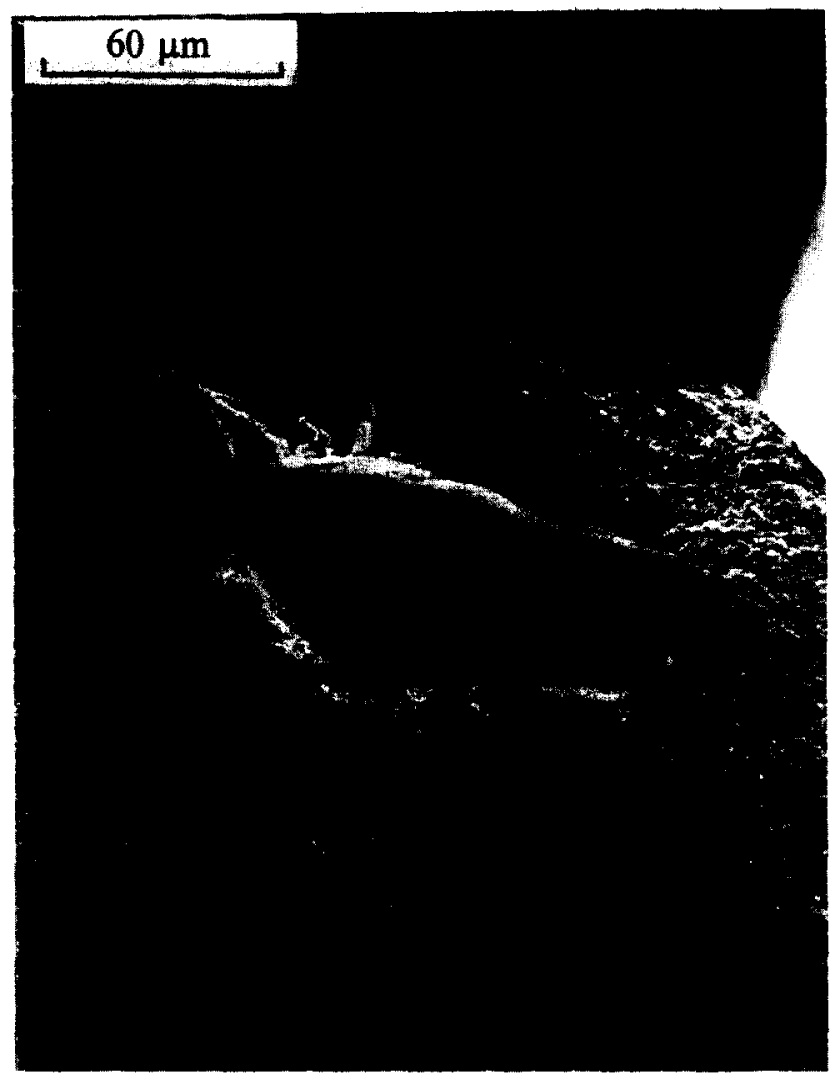

(a)

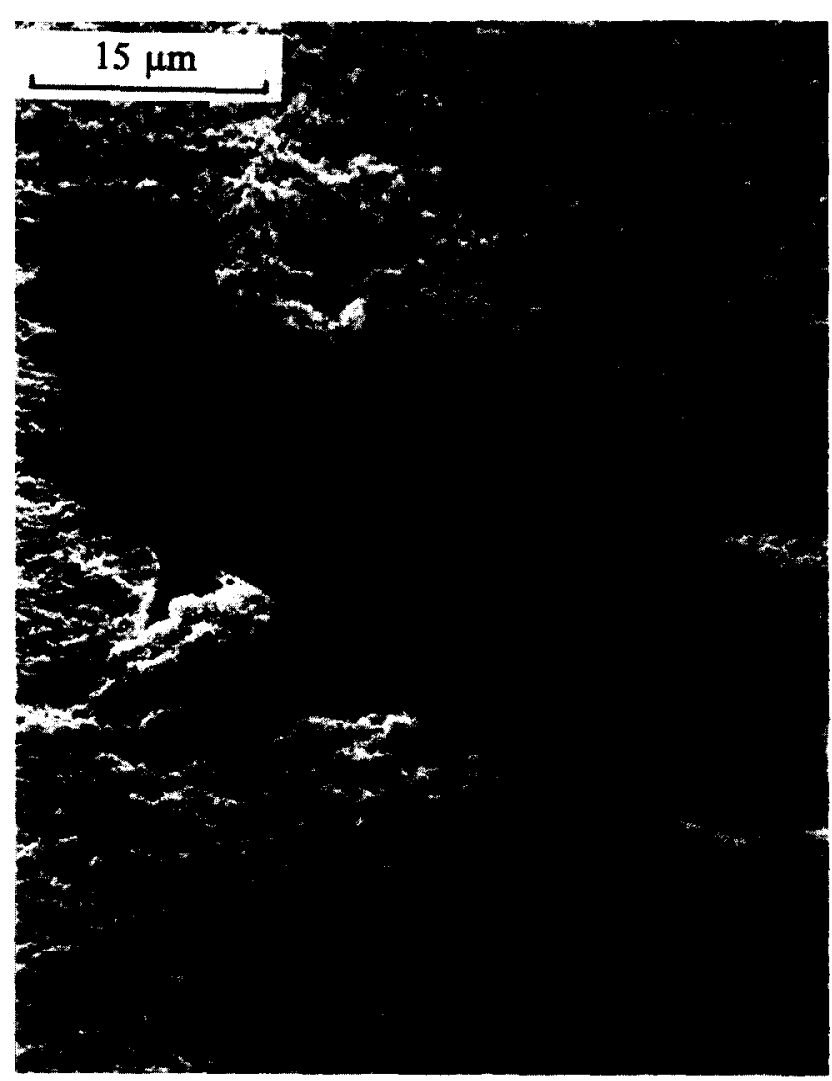

(b)

Fig. 9. An alumina inclusion acting as a fracture origin observed in the fracture surfaces of the sinter-forged or pressureless sintered samples.

ture by pressureless sintering at lower temperatures such as $1150^{\circ} \mathrm{C}$. During sinter-forging, a shear deformation is exerted on the compact so that large pores (or defects) can become oval-shaped 
and subsequently fragmented into smaller ones as indicated in Ref. 12. The small pores can then disappear easily with increasing shear strain. The experimental results of Kellett and Lange ${ }^{28}$ clearly show that shear deformation is responsible for the elimination of pores by a change of pore shape. The shear deformation process can even prevent the formation of crack- or pore-like flaws during the densification process. Previous experimental and theoretical results ${ }^{12,28}$ indicate that a maximum compressive strain of 0.6 is needed to remove large pores of spherical shape. This value can be less for non-spherical pores and depends on the initial aspect ratio of the minimum and maximum diameter of the ellipsoidal pore. In our study, a final shear strain of 0.5 is obtained and leads to the elimination of process flaws. The effect of shear deformation on densification during the sinter process also leads to dense materials in shorter sintering times and even at lower sintering temperatures. The effectiveness in reducing flaws and increasing densification through sinter-forging was also observed for $\mathrm{Al}_{2} \mathrm{O}_{3}{ }^{12}$ and ZTA. " Sung et $a l .{ }^{27}$ indicated that the fracture origin flaws follow an 'order of severity' in which crack-like flaws and larger pores are more severe fracture origins than inclusions. This may suggest that, even though the alumina inclusions that we found have much larger dimensions than the crack-like flaws, the latter, however, have a stronger influence on fracture strength. Hence the improvement in reliability by sinter-forging should be attributed to the elimination of more severe fracture origins such as porelike and crack-like flaws.

The creep behaviour of ultra-fine TZP materials during sinter-forging, especially in the final sintering stage, has been interpreted as interface-reaction-controlled or grain-boundary-diffusion controlled grain boundary sliding. ${ }^{13}$ Sinter-forging thus not only eliminates the flaws in the sintered bulk, but also changes the grain boundary morphology. In order to demonstrate the possible change of the grain boundary morphology by sinter-forging, the hard-sphere description of Gleiter et al. ${ }^{29,30}$ for nanocrystalline materials is adopted. In this description the materials consist of two phases: a crystalline bulk component formed by regular lattice atoms (spheres) and an interfacial (grain boundary) component comprising all atoms which are situated in grain boundaries. A simple twodimensional model of an ultra-fine-grained ceramic is given in Fig. 10. The interfacial atoms generally are situated in regular lattice positions, but in reality these atoms will relax from these sites (see the local area of A in Fig. 10(a)). The grain boundary phase may exhibit a different solid state structure with a more random atomic arrange- ment in which certain interatomic spacings are not filled completely due to incoherence between adjacent crystal lattices, ${ }^{30}$ e.g. the local area $\mathrm{B}, \mathrm{C}$ in Fig.10(a). This situation is especially probable when an irregular surface prevails frequently, as is the case for very small grains (nanocrystals). For ceramics obtained by pressureless sintering, large interatomic spacings might then be formed easily at the grain boundaries and result in a relatively thick grain boundary layer with micro-defects such as the local areas A, B and C in Fig. 10(a). If samples obtained by pressureless sintering contain an amorphous layer at grain boundaries due to impurity segregation (see Fig. 11(A)), the grain boundary component consists of the amorphous film and the interface atoms. In such cases, the presence of an amorphous layer may also make the grain boundaries weaker and lead to a further decrease in the grain boundary bonding strength. A grain boundary film with a thickness of about $1-2 \mathrm{~nm}$ is observed by TEM in pressureless sintered ZY5 materials ${ }^{13}$ using the Fresnel fringe imaging technique.

During sinter-forging, shear deformation controlled by interface reaction or grain boundary diffusion ${ }^{13}$ results in a rearrangement of the grain boundary component. Some impurities which are segregated to the grain boundaries are moved to grain boundary junctions or are partly eliminated by the crystallization during sinter-forging. The low energy traps are gradually filled and interatomic spacings are reduced. This process results in a thinner and more regular grain boundary layer (see Fig. 10(b)) as well as discontinuous amorphous films (see Figs 11(B) and (C)). The observation of the high resolution TEM image by Boutz et al. ${ }^{13}$ shows the absence of amorphous phases or the existence of discontinuous amorphous films at grain boundaries of sinter-forged

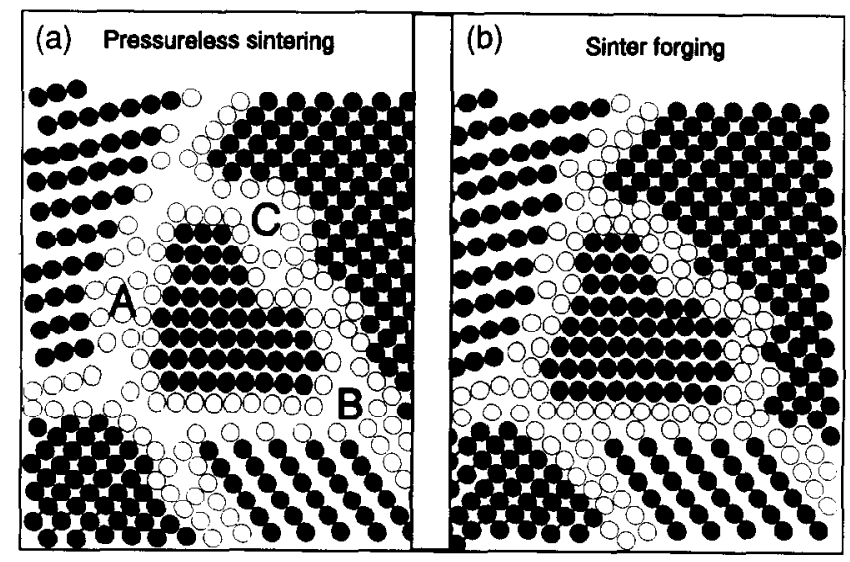

Fig. 10. Schematic representation of ultra-fine-grained ceramics distinguishing between the atoms associated with the individual crystals (solid circles) and those constituting the grain boundary network (open circles). The boundary atoms are shown in regular lattice positions, but in reality will relax to form different atomic arrangements (based on the model in Refs 29 and 30). 


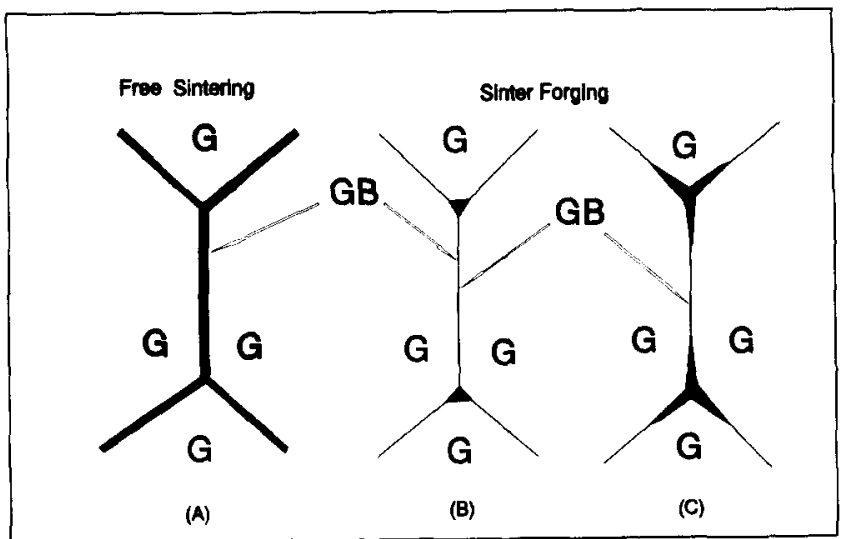

Fig. 11. Model of the physical-chemical state of the grain boundaries of TZP ceramics after pressureless sinter or sinterforging (G: grain, GB: grain boundary).

ZY5. A more detailed discussion of this is given by Boutz et al. ${ }^{13}$ XPS results obtained by Boutz et al. ${ }^{13}$ show that there is a significant decrease in yttrium, aluminium and silicon concentration at the grain boundaries of sinter-forged samples. This may result in enhanced bonding strength between interface atoms from differently oriented crystallites. The improved grain boundaries might result in a higher resistance to plastic deformation in local areas, resulting in higher classical Vickers hardness for sinter-forged TZP samples than that for pressureless sintered samples.

Krell \& Blank ${ }^{6}$ pointed out that the presence of a relatively thick grain boundary layer can easily cause the formation of cracks at grain boundaries and provide an easy path for crack propagation. The improved grain boundary bonding strength by sinter-forging leads to a large fracture energy in sinter-forged samples which, in turn, increases the resistance to crack propagation. This results in an increase in grain boundary toughness $\left(K_{\mathrm{IC}}{ }^{\mathrm{gb}}\right)$. As indicated by Krell et al. ${ }^{13}$ a higher grain boundary toughness $\left(K_{\mathrm{IC}}{ }^{\mathrm{gb}}\right)$ gives a higher macroscopic toughness.

\section{Conclusions}

(1) Dense, ultra-fine grained (180-190 nm) ZY5 and $\mathrm{ZY} 4 \mathrm{Ce} 4$ ceramics were obtained by both sinter-forging and pressureless sintering at $1150^{\circ} \mathrm{C}$. The sintering time necessary to obtain high density $(>95 \%)$ can be reduced by sinter-forging, i.e. sinter-forging can significantly improve the densification rate of TZP ceramics.

(2) Sinter-forging with a large shear strain (about 0.5 ) results in the absence of large pores or cracklike flaws which are present in pressureless sintered samples. It also results in an improvement of the reliability
(Weibull modulus of 21) of sinter-forged samples compared to pressureless sintered ones (Weibull modulus of 8).

(3) After sinter-forging, the grain boundaries are strengthened by suppressing impurity segregation and by hindering the formation of a continuous amorphous film at grain boundaries due to shear deformation. Sinter-forging also results in a higher Vickers microhardness, an increase in fracture energies and fracture toughness compared to pressureless sintered samples. The strengthening of the grain boundaries, which is responsible for the increase of fracture toughness, is partially maintained at high temperatures. A fracture toughness $K_{I C}$ of $10 \mathrm{MPa} \mathrm{m}^{1 / 2}$ is obtained for ultra-fine grained TZP made by sinter-forging. A fracture energy of $300-330 \mathrm{~J} / \mathrm{m}^{2}$ is calculated for these materials. No irreversible phase transformation toughening was detected.

(4) The bending strength in sinter-forged samples is slightly increased by the strengthened grain boundaries. The Weibull modulus strongly increases in this case, which indicates that the strength is more sensitive to the flaw sizes and flaw size distribution. The presence of some large alumina inclusions limited the increase of bending strength in sinter-forged samples.

\section{Acknowledgments}

The authors are grateful to Miss Petra M. V. Bakker for the powder preparation, Mr Joop Snoeyenbos for machining and polishing, Mr Jaap Boeijsma for XRD measurements, Mr Marc Smithers for SEM observations. This research was partly supported by the Innovative Research Program on Technical Ceramics (IOP-TK) with the financial aid of the Dutch Ministry of Economic Affairs.

\section{References}

1. Watanabe, T., Grain Boundary Design for Desirable Mechanical Properties. Journal de Physique, 49 Collogue C5 (1988) 507-19

2. Boutz, M. M. R., Chen, C. S., Winnubst, A. J. A. \& Burggraaf, A. J., Characterisation of Grain Boundaries in Superplastically Deformed Y-TZP Ceramics. J. Am. Ceram. Soc., 77(10) (1994) 2632-40.

3. Lim, L. C. \& Watanabe, T., Fracture Toughness and Brittle-Ductile Transition Controlled by Grain Boundary Character Distribution (GBCD) in Polycrystals. Acta Metal. Mater., 38(12) (1990) 2507-16.

4. Krell, A., Woltersdorf, J., Pippel, E. \& Schulze, D., On Grain Boundary Strength in Sintered $\mathrm{Al}_{2} \mathrm{O}_{3}$. Philosophical Magazine A, 51(5) (1985) 765-76. 
5. Griffith, A. A., Phil. Trans. R. Soc., A221 (1920) 163.

6. Krell, A. \& Blank, P., Inherent Reinforcement of Ceramic Microstructure by Grain Boundary Engineering. J. Eur. Ceram. Soc., 9 (1992) 309-22.

7. Burggraaf, A. J., Stuijts Memorial Lecture 1991: Some New Developments in Ceramic Science and Technology. J. Eur. Ceram. Soc., 9 (1992) 245.

8. Burggraaf, A. J., Winnubst, A. J. A. \& Verweij, H., Dense and Porous Nanostructured Ceramics and Composites. In Third Euro-Ceramics, Vol. 3, ed. P. Durén and J. F. Feméndez, 1993, pp. 561-76.

9. Boutz, M. M. R., Winnubst, A. J. A., Burggraaf, A. J., Nauer, M. \& Carry, C., Low Temperature Superplastic Flow of Yttria Stabilized Tetragonal Zirconia Polycrystals. J. Eur. Ceram. Soc., 13(2) (1994) 103-11.

10. Theunissen, G. S. A. M., Bouma, J. S., Winnubst, A. J. A. \& Burggraaf, A. J., Mechanical Properties of UltraFine Grained Zirconia Ceramics. J. Mater. Sci., 27 (1992) 4429.

11. He, Y. J., Winnubst, A. J. A., Verweij, H. \& Burggraaf, A. J., Improvement of Mechanical Properties of Zirconia Toughened Alumina by Sinter-forging. J. Mater. Sci., 29(22) (1994) 5868-74

12. Venkatachari, K. R.\& Raj, R., Enhancement of Strength through Sinter Forging. J. Am. Ceram. Soc., 70(7) (1987) 514-20.

13. Boutz, M. M. R., Winnubst, A. J. A., Burggraaf, A. J., Nauer, M. \& Carry, C., Low Temperature Sinter Forging of Nanustructured Y-TZP and YCe-TZP. J. Am. Ceram. Soc., 78(1) (1995) 121-8.

14. He, Y. J., Winnubst, A. J. A., Verweij, H. \& Burggraaf, A. J., Sinter Forging of Zirconia Toughened Alumina. $J$. Mater. Sci., 29(24) (1994) 6505-12.

15. Boutz, M. M. R., Winnubst, A. J. A. \& Burggraaf, A. J., The Effect of Ceria-Codoping on Chemical Stability and Fracture Toughness of Y-TZP. J. Mater. Sci., 30 (1995) 1854-62.

16. Groot Zevert, W. F. M., Winnubst, A. J. A., Theunissen, G. S. A. M. \& Burggraaf, A. J., Powder preparation and compaction behaviour of fine-grained Y-TZP. J. Mater. Sci., 25 (1990) 3449.

17. Den Exter, P., Synthesis, Microstructure and Mechanical Properties of Zirconia-Alumina Composites. PhD Thesis. University of Twente, Enschede, The Netherlands, 1991.
18. Toraya, H., Yoshimura, M. \& Sōmiya, S., Calibration Curve for Quantitative Analysis of the MonoclinicTetragonal $\mathrm{ZrO}_{2}$ System by X-Ray Diffraction. J. Am. Ceram. Soc.,67 (1984) C-119.

19. Mendelson, M. I., Average Grain Size in Polycrystalline Ceramics. J. Am. Ceram. Soc., 52(8) (1969) 443-6

20. Sullivan, J. D. \& Lauzon, P. H., Experimental Probablity Estimators for Weibull Plots. J. Mater. Sci. Lett., 5 (1986) 1245.

21. Tabor, D., The Hardness of Solids. Rev. Phys. Techn., 1 (1970) 145-79.

22. Klug, K. P. \& Alexander, L. E., X-ray Diffraction Procedures. John Wiley and Sons, New York, 1974.

23. Theunissen, G. S. A. M., Microstructure, Fracture Toughness and Strength of (Ultra)Fine-Grained Tetragonal Zirconia Ceramics. PhD Thesis, University of Twente, Enschede, The Netherlands, 1991.

24. Krell, A., Improved Hardness and Hierarchic Influences on Wear in Submicron Sintered Alumina. 5th Int. Conf. Science of Hard Materials, Maui (Hawaii), 20-24 Feb. 1995, Mater. Sci. Eng. A., special issue.

25. Rice, R. W., Freiman, S. W., Pohanka, R. C., Mecholsky Jr, J. J. \& Wu, C. C., Fracture Mechanics of Ceramics, ed. R. C. Bradt, D. P. H. Hasselman \& F. F. Lange, Plenum Press, New York, 1978, pp. 849-76.

26. Lange, F. F. \& Metcalf, M., Processing-Related Fracture Origins: II. Agglomerate Motion and Cracklike Internal Surface Caused by Differential Sintering. J. Am. Ceram. Soc., 66 (6) (1983) 398-406.

27. Sung, J. \& Nicholson, P. S., Strength Improvement of Yttria-Partially-Stabilized Zirconia by Flaw Elimination. J. Am. Ceram. Soc., 71(9) (1988) 788-95.

28. Kellett, B. J. \& Lange, F. F., Experiments on Pore Closure During Hot Isostatic Pressing and Forging. J. Am. Ceram. Soc., 71(1) (1988) 7-12.

29. Gleiter, H., Materials with Ultrafine Grain Sizes. 1980 Deformation of Polycrystals, ed. N. Hansen, A. Horsewell, T. Leffers \& L. Libholt, 2th Ris $\phi$ Int. Symp. on Metallurgy and Materials Science, Ris $\phi$ Nat. Lab., Roskilde, Denmark, 1981, pp. 15-21.

30. Xhu, X., Birringer, R., Herr, U. \& Gleiter, H., X-ray Diffraction Studies of the Structure of NanometerSized Crystalline Materials. Phys. Rev. B., 35 (1987) 9085-90. 